\title{
A cluster randomized trial to improve adherence to evidence-based guidelines on diabetes and reduce clinical inertia in primary care physicians in Belgium: study protocol [NTR 1369]
}

\author{
Liesbeth Borgermans*1, Geert Goderis ${ }^{1}$, Carine Van Den Broeke ${ }^{1}$, \\ Chantal Mathieu ${ }^{2}$, Bert Aertgeerts ${ }^{1}$, Geert Verbeke ${ }^{3}$, An Carbonez ${ }^{3}$, \\ Anna Ivanova ${ }^{3}$, Richard $\mathrm{Grol}^{4}$ and Jan Heyrman ${ }^{1}$
}

\author{
Address: ${ }^{1}$ Catholic University Leuven, Department of General Practice, Kapucijnenvoer 33/J Box 7001, 3000 Leuven, Belgium, ${ }^{2}$ University \\ Hospitals Leuven, Experimental Medicine, Herestraat 49, 3000 Leuven, Belgium, ${ }^{3}$ Catholic University Leuven, Leuven Statistics Research Centre \\ (LStat), Celestijnenlaan 200 B, 3001 Heverlee, Belgium and ${ }^{4}$ Radboud University of Nijmegen, Faculty of Medicine, Centre for Quality of Care, \\ PO BOX 9101, KWAZO 114, 6500 HB Nijmegen, The Netherlands \\ Email: Liesbeth Borgermans* - liesbeth.borgermans@med.kuleuven.be; Geert Goderis - geert.goderis@med.kuleuven.be; Carine Van \\ Den Broeke - carine.vandenbroeke@med.kuleuven.be; Chantal Mathieu - chantal.mathieu@uz.kuleuven.be; \\ Bert Aertgeerts - bert.aertgeerts@med.kuleuven.be; Geert Verbeke - geert.verbeke@med.kuleuven.be; \\ An Carbonez - an.carbonez@ucs.kuleuven.be; Anna Ivanova - anna.ivanova@ucs.kuleuven.be; Richard Grol - r.grol@kwazo.nl; \\ Jan Heyrman - jan.heyrman@med.kuleuven.be \\ * Corresponding author
}

Published: 6 October 2008

Implementation Science 2008, 3:42 doi:10.1/86/1748-5908-3-42
Received: 30 June 2008

Accepted: 6 October 2008

This article is available from: http://www.implementationscience.com/content/3///42

(c) 2008 Borgermans et al; licensee BioMed Central Ltd.

This is an Open Access article distributed under the terms of the Creative Commons Attribution License (http://creativecommons.org/licenses/by/2.0), which permits unrestricted use, distribution, and reproduction in any medium, provided the original work is properly cited.

\begin{abstract}
Background: Most quality improvement programs in diabetes care incorporate aspects of clinician education, performance feedback, patient education, care management, and diabetes care teams to support primary care physicians. Few studies have applied all of these dimensions to address clinical inertia.
\end{abstract}

Aim: To evaluate interventions to improve adherence to evidence-based guidelines for diabetes and reduce clinical inertia in primary care physicians.

Design: Two-arm cluster randomized controlled trial.

Participants: Primary care physicians in Belgium.

Interventions: Primary care physicians will be randomly allocated to 'Usual' (UQIP) or 'Advanced' (AQIP) Quality Improvement Programs. Physicians in the UQIP will receive interventions addressing the main physician, patient, and office system factors that contribute to clinical inertia. Physicians in the AQIP will receive additional interventions that focus on sustainable behavior changes in patients and providers.

Outcomes: Primary endpoints are the proportions of patients within targets for three clinical outcomes: I) glycosylated hemoglobin $<7 \%$; 2) systolic blood pressure differences $\leq 130 \mathrm{mmHg}$; and 3) low density lipoprotein/cholesterol $<100 \mathrm{mg} / \mathrm{dl}$. Secondary endpoints are individual improvements in 12 validated parameters: glycosylated hemoglobin, low and high density lipoprotein/cholesterol, total cholesterol, systolic blood pressure, diastolic blood pressure, weight, physical exercise, healthy diet, smoking status, and statin and anti-platelet therapy. 
Primary and secondary analysis: Statistical analyses will be performed using an intent-to-treat approach with a multilevel model. Linear and generalized linear mixed models will be used to account for the clustered nature of the data, i.e., patients clustered withinimary care physicians, and repeated assessments clustered within patients. To compare patient characteristics at baseline and between the intervention arms, the generalized estimating equations (GEE) approach will be used, taking the clustered nature of the data within physicians into account. We will also use the GEE approach to test for differences in evolution of the primary and secondary endpoints for all patients, and for patients in the two interventions arms, accounting for within-patient clustering.

Trial Registration: number: NTR 1369.

\section{Background}

Diabetes management is a complex process requiring physiological, psychological, and social interventions $[1,2]$. Although considerable evidence supports the use of pharmacological interventions in diabetes care $[3,4]$, the best way to improve health outcomes using non-pharmacological 'complex interventions' is often unclear [5]. A number of complex interventions target improvements in patient, provider, and organizational aspects of diabetes care [6]. The active components of these complex interventions are essential to their proper functioning and may act both independently and interdependently [7]. The Chronic Care Model (CCM) is often used as a conceptual framework to underpin complex interventions in diabetes care $[8,9]$. According to this model, patient outcomes such as good control of risk factors are associated with the presence of one or more interrelated components: community resources, self-management support, delivery system redesign, decision support, clinical information systems, and organizational support [8]. Most quality improvement programs in diabetes care cover several dimensions of the CCM, in particular those supported by substantial evidence of improved outcomes of care in selected populations [10]. Clinician education and dissemination of guidelines [11,12], feedback on performance [13], patient education $[14,15]$, care management $[16,17]$, and diabetes care teams (DCTs) to support primary care physicians [18-20] represent examples of such interventions. Few studies have applied all dimensions of the CCM to address non-adherence to evidence-based guidelines and to reduce 'clinical inertia' in primary care physicians [2123].

Clinical inertia is defined as a lack of treatment initiation or intensification in a patient that is not achieving evidence-based goals of care [24]; this is consistent with the definition of medical errors given by the Institute of Medicine $[25,26]$. Clinical inertia increases the likelihood of adverse outcomes in a high proportion of patients, but it may take years for poorer clinical outcomes to become apparent [27]. Numerous authors, including those who report on clinical inertia, have defined three principal sources for non-adherence to evidence-based guidelines and clinical inertia: physician factors, patient factors, and office system and organizational factors [28-30]. Physician factors that contribute to clinical inertia include an overestimation of care actually delivered, a failure to identify and manage comorbid conditions, disagreement with evidence-based goals of care and the use of 'soft reasons' to avoid intensification of therapy (e.g., patient refusal) [31,32]. Patient factors that contribute to clinical inertia are limited motivation or resistance to adopting lifestyles that support optimal disease care, which stresses the importance of patient empowerment as a cornerstone to high-quality diabetes care [33,34]. Office system and organizational factors that contribute to clinical inertia are the absence of decision support and a team approach to care. These three sources interact in complex ways, and interventions to reduce clinical inertia therefore need to be multifactorial in nature. Here, we describe a study protocol of a cluster randomized trial. We have chosen the physician's practice as the unit of randomization since this was considered the most feasible method of conducting the trial. We plan to compare two different interventions for improving adherence to evidence based guidelines and reducing clinical inertia in primary care physicians.

\section{Aim of the study}

Our program goal is to improve adherence to evidencebased guidelines and to reduce clinical inertia in primary care physicians, and to therefore improve the management of glycemic control and cardio-vascular risk factors in persons with diabetes.

\section{Scientific hypothesis}

One hypothesis is that an advanced quality improvement program (AQIP) significantly improves clinical outcomes in persons with type 2 diabetes compared to a usual quality improvement program (UQIP). Subgroup analyses can analyze the effect of the program in the two intervention arms using cut-off values. The second hypothesis is that persons with type 2 diabetes who make use of a DCT will have significantly better outcomes compared to non-users of the DCT, regardless of their intervention arm. 


\section{Methods \\ Study design}

The study is an open pragmatic cluster randomized trial with before/after measurements and two intervention arms. A cluster design is necessary because randomization is performed on a practice level, the intervention happens on the physician level, but a large part of the data are analyzed at the patient level. The implementation period of the trial is 18 months.

\section{Participants}

All 379 active primary care physicians (PCPs) in the project region are invited to participate in the project. These PCPs work in a semi-rural setting with 357,000 inhabitants and serve predominantly Caucasian patients with type 2 diabetes mellitus. PCPs provide care for approximately $80 \%$ of patients with type 2 diabetes, and are often the sole providers of care. The only inclusion criterion for the providers is agreeing to recruit all patients with type 2 diabetes mellitus to prevent selection bias. In addition, PCPs will be asked to screen more systematically for new type 2 diabetes mellitus patients during the seven months after registration begins. Diabetes is defined in accordance with the 2003 ADA criteria [35] with PCPs making the final diagnosis.

Only patients with type 2 diabetes mellitus will be included in the study, regardless of age. Patients who cannot provide informed consent will be excluded from the study.

\section{Intervention}

The UK Medical Research Council (MRC) framework for the development and evaluation of complex interventions for randomized control trials (RCT) is used as a theoretical guide to designing the intervention [6]. The MRC framework allows for the development of a high-quality study design, execution, generalizability of the results, and outlines five key phases for intervention development: a preclinical/theoretical phase, a modeling phase, a phase of exploratory trials prior to the randomized controlled trial (RCT), the trial itself, and long-term implementation [36]. All phases except phase two (exploratory trial phase) and phase five (long-term implementation phase) are incorporated here. A detailed overview is provided in Table 1.

\section{Preclinical phase of the MRC framework}

This phase involves exploration of the relevant theory and evidence to refine the underlying hypotheses, conceptual model, interventions, and indicators. We have previously performed a review of systematic reviews for this purpose [37]. A total of 21 systematic reviews (1989-2006) were included in the review and represented 185 diabetes care programs. Conceptual background, goals, settings, type of programs, type and number of interventions, type and number of indicators, and (cost) effectiveness were evaluated in both the 21 systematic reviews and the individual diabetes care programs. The program is further built on the CCM [8,9] and principles of integrated care. As there is no unambiguous definition of integrated care, we further build on the definitions of Ellrodt and colleagues [38], Mur-Veeman and colleagues [39], and the Disease Management Association of America (DMAA) [40]. We consider integrated care as 'an organizational process of continuous coordination of evidence-based and relevant interventions across the entire health care delivery system and care continuum that seeks to maximize quality of care tailored to the needs of every individual patient while minimizing costs'.

Besides exploring relevant theory and evidence, the local context in terms of existing national and regional governmental policies, characteristics of the region, and perceived barriers to high-quality diabetes care were extensively studied with regard to their impact on the content and execution of the study protocol. We have previously organized stakeholder interviews, including a representative group of 18 Belgian opinion leaders and experts in diabetes care [41].

\section{Modeling phase}

In the modeling phase, we delineated the components of our complex intervention and the underlying mechanisms by which they influence the outcomes. We sought to understand the pathways by which the problem is caused and sustained, including all barriers to high-quality diabetes care. We also explored whether the pathways were amenable to change, and if so, at which points. Finally, we estimated potential for improvement in both process and primary outcomes. This analysis produced the best achievable combination of intervention components, implementation strategies, and intensities of care delivery, as well as the identification of feasible and valid outcome measures.

\section{Interventions}

Two separate groups are defined: the first group will receive a usual quality improvement program (UQIP), and a second group will receive an advanced quality improvement program (AQIP). Physicians can make use of program services on a voluntary basis.

The UQIP arm will aim to improve adherence to evidencebased guidelines and to reduce the rate of clinical inertia in PCPs. The term 'usual' is applied because these interventions address the principal factors contributing to clinical inertia (physician, patient, and office system factors) and represent standard requirements for what is considered quality of diabetes care in most health care systems 
Table I: The MRC Framework applied for the development and evaluation of a complex intervention in diabetes care.

\begin{tabular}{|c|c|c|c|}
\hline \multicolumn{4}{|l|}{ Phases } \\
\hline \multicolumn{4}{|c|}{ Phase I- Preclinical theory (Why should the intervention work?) } \\
\hline Content & Methods & Results & Publications \\
\hline $\begin{array}{l}\text { - Collecting evidence on the } \\
\text { effectiveness of multifaceted diabetes } \\
\text { intervention programs - Identification } \\
\text { of evidence on appropriate outcome } \\
\text { indicators } \\
\text { - Influence of local context }\end{array}$ & $\begin{array}{l}\text { Review of systematic reviews on } \\
\text { diabetes care programs in } \\
\text { primary care, outpatient, } \\
\text { community and hospital settings } \\
\text { to identify: conceptual } \\
\text { backgrounds of programs, goals, } \\
\text { settings, type of program, type of } \\
\text { interventions, type of indicators, } \\
\text { (cost) effectiveness of programs } \\
\text { and interventions }\end{array}$ & $\begin{array}{l}\text { Overview of best choice of interventions and } \\
\text { indicators, selection of conceptual model, overview } \\
\text { of major confounders, overview of strategic design } \\
\text { issues, overview of barriers to high-quality diabetes } \\
\text { care at the macro, meso and micro level }\end{array}$ & [37] \\
\hline \multicolumn{4}{|c|}{ Phase II- Modeling (How does the intervention work?) } \\
\hline Content & Methods & Results & Publications \\
\hline $\begin{array}{l}\text { - Understanding of the pathways by } \\
\text { which the problem is caused and } \\
\text { sustained } \\
\text { - Exploration of whether the pathways } \\
\text { are amenable to change and, if so, at } \\
\text { which points } \\
\text { - Quantification of the potential for } \\
\text { improvement } \\
\text { (estimates of likely effect size) } \\
\text { - Program development }\end{array}$ & $\begin{array}{l}\text { - Stakeholder interviews to } \\
\text { identify and understand barriers } \\
\text { to high-quality diabetes care in } \\
\text { the Belgian health care system } \\
\text { and multidisciplinary team } \\
\text { meetings to discuss program } \\
\text { development }\end{array}$ & $\begin{array}{l}\text { - Definition a multifaceted intervention/ } \\
\text { implementation strategy and outcome-indicators and } \\
\text { local adaptation of the treatment protocol }\end{array}$ & {$[4 I]$} \\
\hline \multicolumn{4}{|c|}{ Phase III - Exploratory Trials (not performed) } \\
\hline \multicolumn{4}{|c|}{ Phase IV - Randomized Controlled Trial } \\
\hline \multicolumn{4}{|c|}{ The Diabetes Project Leuven (cluster randomized trial) } \\
\hline
\end{tabular}

according to international clinical guidelines [42], and theoretical frameworks on quality of diabetes care in particular [43]. The first intervention arm is innovative to the Belgian healthcare system and adds to available insights from the international literature on how to address clinical inertia in diabetes care.

The AQIP arm will receive similar interventions, but will also include supplementary and experimental interventions that extensively focus on behavior changes in patients and providers. Interventions that focus on the patient aim at a more active involvement of the patient in his/her treatment regimen, with a special focus on lifestyle attitude changes. Improvements in 'patient empowerment' will further decrease clinical inertia by increasing the patient's willingness to intensify his/her treatment $[44,45]$. Interventions that target the PCP focus on improvements in communication patterns with patients, interdisciplinary shared care, and involving PCPs in community campaigns. This multi-factorial approach, with a focus on patient, provider, and organizational aspects of care, is fully in line with the latest insights and findings on high-quality chronic care, and high-quality diabetes care in particular $[9,19,46-53]$.

The differences between the AQIP and the UQIP are outlined further below and in Table 2 .

We will use two classification schemes to incorporate all six dimensions of the CCM based on the classification scheme from Shojania and colleagues [54], who defined eleven distinct categories of quality improvement interventions adapted from the Cochrane Effective Practice and Organization Of Care (EPOC) group [55]. These categories are: patient education, promotion of self-management, clinician education, audit and feedback, case management, team changes, electronic patient registry, clinician reminders, facilitated relay of clinical information to clinicians, patient reminder systems, and continuous quality improvement. Five interventions are not included in the service program as they are either integrated in other interventions of the program (e.g., the patient reminder system is integrated with physician reminder system) or because of complexity in the Belgian 
Table 2: Overview of components of the Usual Quality Improvement Program (UQIP) and Advanced Quality Improvement Program (AQIP).

\begin{tabular}{|c|c|c|}
\hline \multicolumn{3}{|l|}{ Patient } \\
\hline \multicolumn{3}{|c|}{$\begin{array}{l}\text { Lack of adhere to treatment regimen and clinical inertia related to:e.g. Limited motivation or resistance to adopting lifestyles that support optimal } \\
\text { disease care. }\end{array}$} \\
\hline & Usual Quality Improvement Program (UQIP) & $\begin{array}{l}\text { Advanced Quality Improvement Program } \\
\text { (AQIP) }\end{array}$ \\
\hline \multirow[t]{2}{*}{ Patient education } & $\begin{array}{l}\text { Medical assessments and education upon } \\
\text { referral of the PCPs by diabetologist or DCT }\end{array}$ & $\begin{array}{l}\text { Medical assessments and education upon } \\
\text { referral of the PCPs by diabetologist or DCT } \\
\text { (DCT) }\end{array}$ \\
\hline & $\begin{array}{l}\text { = internist, nurse educator, dietician and } \\
\text { ophthalmologist }\end{array}$ & $\begin{array}{l}\text { = internist, nurse educator, flying educator, } \\
\text { dietician, ophthalmologist and health } \\
\text { psychologist }\end{array}$ \\
\hline \multirow[t]{7}{*}{ Promotion of self-management } & ---- & $\begin{array}{l}\text { Education of patients in practice } \\
\text { (by flying educator) }\end{array}$ \\
\hline & --- & Education at patient's home (by flying educator) \\
\hline & ---- & Counseling by health psychologist \\
\hline & --- & Structured educational materials from DCT \\
\hline & ---- & $\begin{array}{l}\text { Structured educational materials from } \\
\text { community organizations }\end{array}$ \\
\hline & ---- & $\begin{array}{l}\text { Group educational sessions for patients and } \\
\text { family members }\end{array}$ \\
\hline & ---- & $\begin{array}{l}\text { Free access to blood monitoring tools for self- } \\
\text { management }\end{array}$ \\
\hline
\end{tabular}

\section{Professional}

Lack of adherence to guidelines and clinical inertia related to:e.g. Overestimation of care actually delivered, a failure to identify and manage comorbid conditions, unawareness or disagreement with evidence-based goals of care and 'soft reasons' to avoid intensification of therapy.

Clinician education

Feedback

Reminders

\section{Organisational}

Lack of office system support and organizational aspects of care related to clinical inertia:e.g. Lack of decision support and a team approach to care. Usual Quality Improvement Program (UQIP)

Team changes

DCT operating close to regular care
Usual Quality Improvement Program (UQIP)

Distribution of treatment protocol

Two post-graduate educational sessions

Evidence based guidelines

The use of insulin

Standard educational materials

$---$

At start and end of project: summary of clinical performance

----

Clinical reminders at start and end of project

----
Advanced Quality Improvement Program (AQIP)

Distribution of treatment protocol

Four post-graduate educational sessions provided by diabetologist (opinion leader): Evidence-based guidelines and principles of shared care

The use of insulin

Patient-centered counseling

Peer review

Extended educational materials

Inviting PCPs during DCT meetings to discuss patient cases

Providing structured communication forms to PCPs by DCT

Distribution of shared care protocol + referral indication

Every 3 months: summaries of clinical performance

Every three months: benchmarking feedback

Every three months: Clinical reminders

Every three months: Shared care reminders
Advanced Quality Improvement Program (AQIP)

Active instalment of DCT operating under supervision of a diabetologist from a University Hospital

Diabetes Program manager providing logistic support to PCPs

Introduction of shared care protocol Active encouragement by DCT and scientific team of PCPs to use shared care protocol 
Table 2: Overview of components of the Usual Quality Improvement Program (UQIP) and Advanced Quality Improvement Program (AQIP). (Continued)

\begin{tabular}{|c|c|c|}
\hline & --- & $\begin{array}{l}\text { Referral arrangements } \\
\text { Active encouragement by DCT and scientific } \\
\text { team to adhere to referral arrangements }\end{array}$ \\
\hline & --- & $\begin{array}{l}\text { Liaison activities by DCT towards in-hospital } \\
\text { DCT in secondary care }\end{array}$ \\
\hline & --- & Involvement of independent pharmacists \\
\hline Continuous quality improvement & Quality Assurance Team & Quality Assurance Team \\
\hline
\end{tabular}

primary health care system (case management, audit, electronic patient registry, and facilitated relay of clinical information to clinicians). The different implementation strategies are derived from an overview by Grol and Wensing [56], who have summarized thirteen important theories and models related to the implementation of change to improve diabetes care. These theories/models relate to individual professionals/patients, the social context, and the organizational and economic context.

\section{Level one: patient}

Patient education/promotion of self-management

Both patients in the AQIP and UQIP arms can be referred by their PCP to a DCT to receive a medical assessment by an internist as well as to receive patient education, dietary advice, and examination by an ophthalmologist. This core membership of internists, nurse educators, dieticians, and ophthalmologists reflects the basic requirements of diabetes treatment: nutrition, medication, self-monitoring, selfmanagement, and the management of risk factors [57]. Physicians from both the AQIP and UQIP can ask internists/diabetologists for advice on complex patient cases, with or without patient referral. Educational services and promotion of self-management to patients of the AQIP and UQIP are only provided upon referral of the physician. Nurse educators have received a post-graduate one-year training program on diabetes nursing care. The nurse educator applies individual patient counseling, didactic goal-setting, and situational problem-solving as key educational methods to patients in the AQIP, whereas patients from the UQIP receive services approximating regular care, i.e., individual patient counseling. Physicians from both the AQIP and UQIP can consult dieticians for complementary dietary advice or can refer their patients to discuss information on meal algorithms, dietary strategies, and tailoring food intake to meet the patients' lifestyle, motivation, and specific needs [57]. Education on lifestyle changes, identification of barriers to diabetes selfmanagement, and stress management will be provided by a health psychologist to patients in the AQIP-program after physician referral.

Patients in the AQIP can receive additional services, including group educational sessions for both patients and relatives, education at home or at the physician's practice (provided by a traveling educator), structured and printed educational materials from the DCT and community organizations, and free tools for self-monitoring of blood glucose levels.

\section{Level two: professional}

\section{Clinician education}

Interventions for clinician education include an increased understanding of principles guiding clinical care or awareness of specific recommendations for the patient population using a treatment and shared care protocol, as well as four post-graduate educational sessions based on the Transtheoretical Model of Change [58]. The first session will involve training on the use of evidence-based guidelines and the principles of shared care. A second and a third session will focus on the use of insulin and patientcentered counseling. A fourth session will be set up as a peer review session. Educational messages are delivered, for most part, by a locally well-known diabetologist ('opinion leader') using techniques of group academic detailing [59]. Providing clinical leadership in secondary care is important for PCPs working in an unstructured and thus non-integrated health care environment.

The UQIP will incorporate only the first two sessions. AQIP physicians can attend all four sessions and will also receive extended educational materials. Physicians from both groups will receive accreditation points from a national system for their participation at the educational sessions.

\section{Feedback}

Feedback interventions, provided by a program manager to the physicians, will include summaries of clinical performance of diabetes care delivered to individual patients over a three-month period. AQIP physicians will receive ongoing benchmarking feedback, whereas the UQIP will only receive benchmarking feedback at the start and end of the project. Feedback includes the percentage of a physician's patients who achieve target levels for glycosylated hemoglobin, LDL, total cholesterol and triglycerides, systolic/diastolic blood pressure, an eye and foot examination, aspirin and statin prescriptions, anti-hypertensive medication, smoking status, and weight loss. 


\section{Clinician reminders}

Clinician reminders for physicians of the AQIP are combined with quarterly feedback by the program manager and reminders to make use of the DCT if treatment targets are not met. Physicians are asked to remind their patients about upcoming appointments. Patients are asked by the physicians to make use of a diabetes passport in which the appointments are noted together with important treatment results. Physicians of the UQIP do not receive clinician/patient reminders nor do they receive reminders on the use of the DCT.

\section{Level three: organisational}

Team changes

Team changes are operationalized in three ways. Initially, a DCT will be installed in two primary care facilities that are run by PCPs. The DCTs will be intensively supervised by a diabetologist from the academic hospital in the project region who provides clinical leadership to the team. All DCT members will receive a 60 -hour in-house training program on the use of a shared care protocol, communication skills, and team dynamics. Key elements of the interdisciplinary team include shared leadership with common goals, shared professional identity, and collaborative, rather than consultative, relationships among members [60]. Team members are expected to engage and learn from each other and to attend scheduled meetings. An experienced counselor and a member of the academic project team will oversee the training program. The DCTs operate in support of the PCPs and actively promote referrals to physicians of the AQIP if treatment targets are not met [61]. Fortnightly interdisciplinary meetings will be organized between the members of the DCT who can invite individual physicians from the AQIP to discuss complex patient conditions.

Nurse educators, dieticians, and the health psychologist will meet their colleagues from a university hospital-based diabetes team and the supervising diabetologist on a quarterly basis to exchange experiences and discuss complex patient cases. Internists will meet with the supervising diabetologist every other month to discuss individual patient cases.

Structured, extensive reports will be provided by members of the DCT to the AQIP because PCPs rank standardized, structured correspondence very high $[62,63]$. Physicians of the UQIP will only receive standard communication forms.

Team changes will also include the active promotion of a diabetes program manager who operates as the central point of referral for the physicians. The program manager will be selected based on the following criteria: strong interpersonal communication skills, the ability to create trust, knowledge of diabetes, and organizational capabilities. The program manager will provide physicians from the AQIP with extended (logistic) support, including physician reminders, providing feedback, liaison activities between the DCT and physicians, organizing group educational sessions, and responding to questions on the study or diabetes-related topics. A project website to facilitate this will be accessible for AQIP and UQIP physicians.

The final team change will be involvement of independent pharmacists in the study. Pharmacists are asked to provide physicians in the AQIP program with medication schemes of their patients upon request. As such, pharmacists can play a more active role in patient monitoring or adjusting medication regimens [64-66].

\section{Continuous quality improvement}

Continuous quality improvement will be assured by an iterative process for assessing quality problems in the implementation of the project, developing solutions to those problems, testing their impacts, and then reassessing the need for further action. For this purpose an interdisciplinary quality assurance team will be established that includes a diabetologist, four PCPs, two nurses, internists, dieticians, and pharmacists. The quality assurance team will be asked to monitor the implementation of the project, as well as evaluate outcome indicators of the project. Meetings will be organized on a regular basis with individual members of the quality assurance team.

\section{Sample size}

The project funding agency requires a sample size of at least one-third of the potential PCPs $(n=379)$, which would capture roughly 2,500 patients with type 2 diabetes mellitus. This sample size allows $80 \%$ power (type II error: 0.20 ) to detect a $20 \%$ relative difference between the intervention arms in the proportion of patients achieving a $10 \%$ improvement in any one of the following: blood pressure, total cholesterol, or HbA1c (type I error: 0.05; assumed intracluster coefficient 0.6; [67] for calculation methods).

\section{Randomization and allocation concealment}

After recruitment, a researcher not involved in the study and blind to the identity of the practices will perform a randomization (by computer-generated numbers) stratified by practice size (solo/duo/group practice) and the presence or absence of an electronic medical recording system. To minimize the possibility of selection bias, all patients within a cluster will be included. Blinding will be ensured for the participating patients, but is not possible at the physician level. 


\section{Data collection}

These practices have no pre-existing registers of diabetic patients. Patients with type 2 diabetes mellitus will be identified using physician memory, searching computerized records, and laboratory lists of patients with increased glycemia or registered glycosylated hemoglobin. Baseline data will be collected over a seven-month period. PCPs will be asked to perform a complete examination and blood analysis at the patient's first visit and to complete a paper form. Identified patients without a visit during the first three months of the project will be invited to participate. The completeness of data capture will be double-checked by a data monitor. Final data will be collected over a seven-month period, with call-backs for non-compliant patients. Patient data sheets include socio-demographic and biomedical data. PCPs will need to indicate whether diabetes is treated by the PCP or in a diabetes clinic.

\section{Primary and secondary endpoints}

The primary endpoints of the study are the proportion of patients reaching ADA targets for three clinical outcomes: HbA1c < 7\%; SBD $\leq 130$ mmHg; and LDL-C < $100 \mathrm{mg} / \mathrm{dl}$. Secondary endpoints are the mean improvements in individual values of 12 validated parameters: HbA1c, LDL-C, HDL-C, Total Cholesterol, SBP, DBP, weight, physical exercise, healthy diet, smoking status, and statin and antiplatelet therapy.

\section{Statistical analysis}

Statistical analyses will be performed using an intent-totreat approach with a multilevel model. Linear and generalized linear mixed models will be used to account for the clustered nature of the data, i.e., patients clustered within PCPs, and repeated assessments clustered within patients. Such models measure how outcomes change over time within patients and whether these changes depend on patient and/or PCP's characteristics, such as the intervention program or DCT use (see hypothesis two). DCT use is defined as having at least one consultation with a member of the team besides the health psychologist and the traveling educator, which are only available for AQIP patients.

We will use generalized estimating equations (GEE), an extension of the quasi-likelihood approach, to test for differences in the evolution of the primary and secondary endpoints for all patients and within the intervention arms. For binary variables, we use the exponential inverse transformation to obtain the $95 \%$ confidence interval for the odds ratio.

Subgroup analyses (see hypothesis one) can distinguish intervention effects using different cut-off values. For HbA1C, three subgroups are defined: patients with HbA1c
$<7 \%$; HbA1c $\geq 7 \%$ and $<8 \%$; and HbA1c $\geq 8 \%$. For SBP, four subgroups are defined: patients with $\mathrm{SBP} \leq 130$ mmHg; SBP > $130 \mathrm{mmHg}$ and $\leq 140 \mathrm{mmHg}$; SBP > 140 $\mathrm{mmHg}$ and $\leq 160 \mathrm{mmHg}$; and SBP > $160 \mathrm{mmHg}$. For LDL-C, four subgroups are defined: patients with LDL-C $<$ $100 \mathrm{mg} / \mathrm{dl} ; \mathrm{LDL}-\mathrm{C} \geq 100 \mathrm{mg} / \mathrm{dl}$ and $<115 \mathrm{mg} / \mathrm{dl}$; LDL-C $\geq$ $115 \mathrm{mg} / \mathrm{dl}$ and < $130 \mathrm{mg} / \mathrm{dl}$; and LDL-C > $130 \mathrm{mg} / \mathrm{dl}$.

Linear mixed models with subject-specific intercepts and slopes are used to test whether subject-specific evolutions are related to initial parameters. HbA1c will be transformed logarithmically to meet the parametric assumptions of the statistical models. All analyses will be performed using SAS, version 9.

\section{Discussion}

Trials of complex interventions inform the drive to provide the most cost-effective health care [7]. RCTs are recognized as the 'gold standard' methodology in quantitative research. Health care interventions are, however, often complex and are always implemented in complex health care settings [68-71]. Complex interventions often have particular characteristics that reduce chances of success in a RCT, including the incorporation of multiple components, targeting multiple outcomes, being difficult to implement or evaluate, or aiming to achieve outcomes that are notoriously difficult to influence [72]. In this context, the complexity of an intervention can present a substantial barrier to its adoption [73]. Complex interventions therefore have greater scope for variation in their delivery and are more vulnerable to one or more components not being implemented correctly [74].

Although we have not performed a pilot trial to assist in data interpretation or clarify process and outcome results, our stakeholder analysis informed our understanding of existing barriers to high-quality diabetes care and allowed us to incorporate innovative change interventions, such as interdisciplinary teams operating on the primary/specialty care interface and educational strategies that target changes in professional practice and improvements in patient empowerment [75]. These hypotheses will be tested using a large group of physicians and patients over an 18-month period. Most quality improvement programs include smaller target groups and shorter intervention periods of six months, which may not be long enough to completely remove the Hawthorne effect. Our study also targets the primary/specialty care interface, an important attribute of high-quality diabetes care [76]. In particular, the clinical leadership and coaching provided by a diabetologist to both the PCPs and the DCT is of particular importance in fragmented systems of care, such as in Belgium. We also explicitly focus on multiple cardiovascular risk factors as the primary outcomes, whereas other studies have not [77]. Finally, we incorporate all six 
dimensions of the CCM, and are only the fourth study in diabetes care to do so $[9,78,79]$. The use of all six dimensions of the CCM permits evaluation of how CCM components are associated with improved outcomes to further refine the model. We therefore explicitly describe how the implementation strategies relate to every dimension of the CCM. Implementation strategies in complex interventions are rarely described [80], even in large-scale implementation studies, which limits the understanding of why an intervention is or is not locally successful [81].

\section{Competing interests}

The authors declare that they have no competing interests.

\section{Authors' contributions}

$\mathrm{BL}, \mathrm{GG}$, and VDBC participated in the study design and drafted the manuscript. MC, AB, VG, CA, IA, GR, and HJ participated in the study design. All authors have read and approved the final manuscript.

\section{Acknowledgements}

The Diabetes Project Leuven (DPL) is funded by a research grant from the National Institute for Health and Disability Insurance in Belgium. The project is approved by the Ethical Committee of the Catholic University of Leuven (project number ML 2719).

\section{References}

I. Gaede P, Vedel P, Larsen N, Jensen GV, Parving HH, Pedersen O: Multifactorial intervention and cardiovascular disease in patients with type 2 diabetes. N Engl J Med 2003, 348:383-393.

2. Miller D: Use of a chronic care model to direct the care of persons with diabetes in the Capital Health Region of BC. Annals of the Royal College of Physicians and Surgeons of Canada 2002, 35:495-499.

3. Gillies CL, Abrams KR, Lambert PC, Cooper NJ, Sutton AJ, Hsu RT, et al: : Pharmacological and lifestyle interventions to prevent or delay type $\mathbf{2}$ diabetes in people with impaired glucose tolerance: systematic review and meta-analysis. BMJ 2007, 334:299.

4. The effect of intensive treatment of diabetes on the development and progression of long-term complications in insulindependent diabetes mellitus. The Diabetes Control and Complications Trial Research Group. N Engl J Med 1993, 329:977-986.

5. Shojania KG, McDonald KM, Wachter RM, Owens DK: Closing the Quality Gap: A Critical Analysis of Quality Improvement Strategies: Series Overview and Methodology. 2004, I: [http:/ /www.ahrq.gov/downloads/pub/evidence/pdf/qualgapl/qualgapl.pdf]. Rockville, MD: AHRQ. Agency for Healthcare Research and Quality. Publication No. 04-005 I-I Last accessed June 2008

6. Medical Research Council MRC: A framework for the development and evaluation of RCTs for complex interventions to improve health. London. Medical Research Council MRC; 2000.

7. Campbell M, Fitzpatrick R, Haines A, Kinmonth AL, Sandercock P, Spiegelhalter $D$, et al.: Framework for design and evaluation of complex interventions to improve health. BM] 2000, 321:694-696.

8. Wagner EH: Chronic disease management: what will it take to improve care for chronic illness? Eff Clin Pract 1998, I:2-4.

9. Piatt GA, Orchard TJ, Emerson S, Simmons D, Songer TJ, Brooks MM, et al:: Translating the chronic care model into the community: results from a randomized controlled trial of a multifaceted diabetes care intervention. Diabetes Care 2006, 29:8II-8I7.

10. Ouwens M, Wollersheim H, Hermens R, Hulscher M, Grol R: Integrated care programmes for chronically ill patients: a review of systematic reviews. Int J Qual Health Care 2005, I 7: |4|-| 46.
II. Lobach DF, Hammond WE: Computerized decision support based on a clinical practice guideline improves compliance with care standards. Am J Med 1997, I 02:89-98.

12. Feder G, Griffiths C, Highton C, Eldridge S, Spence M, Southgate L: Do clinical guidelines introduced with practice based education improve care of asthmatic and diabetic patients? A randomised controlled trial in general practices in east London. BMJ 1995, 3 I I: | 473- | 478.

13. Schectman JM, Schorling JB, Nadkarni MM, Lyman JA, Siadaty MS, Voss JD: The effect of physician feedback and an action checklist on diabetes care measures. Am J Med Qual 2004, 19:207-2I 3.

14. Polonsky WH, Earles J, Smith S, Pease DJ, Macmillan M, Christensen $\mathrm{R}$, et al:: Integrating medical management with diabetes selfmanagement training: a randomized control trial of the Diabetes Outpatient Intensive Treatment program. Diabetes Care 2003, 26:3048-3053.

15. Norris SL, Nichols PJ, Caspersen CJ, Glasgow RE, Engelgau MM, Jack $L$, et al: Increasing diabetes self-management education in community settings. A systematic review. Am J Prev Med 2002, 22:39-66.

16. Closing the gap: effect of diabetes case management on glycemic control among low-income ethnic minority populations: the California Medi-Cal type 2 diabetes study. Diabetes Care 2004, 27:95-103.

17. Aubert RE, Herman WH, Waters J, Moore W, Sutton D, Peterson $B L$, et al: Nurse case management to improve glycemic control in diabetic patients in a health maintenance organization. A randomized, controlled trial. Ann Intern Med 1998, I 29:605-612

18. Legorreta A, Peter A, Ossorio R, Lopez R, Jatulis D, Davidson M: Effect of a Comprehensive Nurse-Managed Diabetes Program: An HMO Prospective Study. Am J Managed Care 1996, 2:1024-1030

19. Wagner $\mathrm{EH}$ : The role of patient care teams in chronic disease management. BMJ 2000, 320:569-572.

20. Weinberger M, Kirkman MS, Samsa GP, Shortliffe EA, Landsman PB, Cowper PA, et al.: A nurse-coordinated intervention for primary care patients with non-insulin-dependent diabetes mellitus: impact on glycemic control and health-related quality of life. J Gen Intern Med 1995, 10:59-66.

21. Renders CM, Valk GD, Griffin SJ, Wagner EH, Eijk VJ, Assendelft WJ: Interventions to improve the management of diabetes in primary care, outpatient, and community settings: a systematic review. Diabetes Care 200I, 24:182I-I833.

22. Phillips LS, Hertzberg VS, Cook CB, El Kebbi IM, Gallina DL, Ziemer DC, et al: The Improving Primary Care of African Americans with Diabetes (IPCAAD) project: rationale and design. Control Clin Trials 2002, 23:554-569.

23. Grol R, Wensing M, Eccles M: Improving patient care: the implementation of change in clinical practice Oxford: Elsevier; 2008.

24. Phillips LS, Branch WT, Cook CB, Doyle JP, El Kebbi IM, Gallina DL, et al.: Clinical inertia. Ann Intern Med 200I, I 35:825-834.

25. Committee on Quality of Health Care in America loM: Crossing the Quality Chasm: A New Health System for the 2 I st Century. [http://www.iom.edu/CMS/8089/5432.aspx]. the IOM Quality of Care Initiative. I-3-200I. Washington DC 2000I Last accessed at June 2007

26. Institute of Medicine: To err is human: building a safer health system. In A report of the Committee on quality of Health Care in America Edited by: Kohn LT, Corrigan JM, Donaldson ME. Washington, DC, National Academy Press; 2000.

27. O'Connor PJ: Overcome clinical inertia to control systolic blood pressure. Arch Intern Med 2003, I 63:2677-2678.

28. O'Connor PJ, Sperl-Hillen JM, Johnson PE, Rush WA, Blitz G: Clinical inertia and outpatient medical errors. Advances in Patient Safety 2007, 2:293-308.

29. Grol $\mathrm{R}$, Buchan $\mathrm{H}$ : Clinical guidelines: what can we do to increase their use? Med J Aust 2006, I 85:30I-302.

30. Cabana MD, Rand CS, Powe NR, Wu AW, Wilson MH, Abboud PA, et al: Why don't physicians follow clinical practice guidelines? A framework for improvement. JAMA 1999, 282:| 458 - 1465.

31. Brown JB, Harris SB, Webster-Bogaert S, Wetmore S, Faulds C, Stewart M: The role of patient, physician and systemic factors in the management of type 2 diabetes mellitus. Fam Pract 2002, 19:344-349. 
32. Kirk JK, Poirier JE, Mattox MG, Thomas PM, Michielutte R: Compliance with national guidelines in patients with diabetes in a family practice clinic. Pharmacotherapy 2002, 22: I 54|-I546.

33. O'Connor PJ, Crabtree BF, Yanoshik MK: Differences between diabetic patients who do and do not respond to a diabetes care intervention: a qualitative analysis. Fam Med 1997, 29:424-428.

34. Pellegrini F, Belfiglio M, De Berardis G, Franciosi M, Di Nardo B, Greenfield S, et al.: Role of organizational factors in poor blood pressure control in patients with type 2 diabetes: the QuED Study Group - quality of care and outcomes in type 2 diabetes. Arch Intern Med 2003, 163:473-480.

35. Standards of Medical Care for Patients With Diabetes Mellitus. Diabetes Care 2008, 26:S33-50S.

36. Campbell NC, Murray E, Darbyshire J, Emery J, Farmer A, Griffiths F, et al:: Designing and evaluating complex interventions to improve health care. British medical journal 2007, 334:455-459.

37. Borgermans L, Goderis G, Ouwens M, Wens J, Heyrman J, Grol R: Diversity in diabetes care programmes and views on highquality diabetes care: Are we in need of a standardized framework? Int J Integr Care 2008, 8:e07.

38. Ellrodt G, Cook DJ, Lee J, Cho M, Hunt D, Weingarten S: Evidencebased disease management. JAMA 1997, 278: I687-1692.

39. Mur-Veeman I, Hardy B, Steenbergen M, Wistow G: Development of integrated care in England and the Netherlands: managing across public-private boundaries. Health Policy 2003, 65:227-24l

40. The Disease Management Association of America [http:// www.dmaa.org]. Accessed at June. 2007

4I. Bastiaens H, Sunaert P, Borgermans L, Wens J, Royen vP, Feyen L, et al.: Visie op de zorg voor diabetes type 2 patiënten in België. Analyse van een bevraging bij achttien belangengroepen. Huisarts Nu 2005, 34:

42. American Diabetes Association: Standards of Medical care in Diabetes. Diabetes Care 2007, 30:

43. Fleming BB, Greenfield S, Engelgau MM, Pogach LM, Clauser SB, Parrott MA: The Diabetes Quality Improvement Project: moving science into health policy to gain an edge on the diabetes epidemic. Diabetes Care 2001, 24:1815-1820.

44. Rhee MK, Slocum W, Ziemer DC, Culler SD, Cook CB, El Kebbi IM, et al.: Patient adherence improves glycemic control. Diabetes Educ 2005, 3 I :240-250.

45. Nicolucci A, Carinci F, Ciampi A: Stratifying patients at risk of diabetic complications: an integrated look at clinical, socioeconomic, and care-related factors. SID-AMD Italian Study Group for the Implementation of the St. Vincent Declaration. Diabetes Care 1998, 2 I: | 439-| 444.

46. Bodenheimer T, Wagner EH, Grumbach K: Improving primary care for patients with chronic illness: the chronic care model, Part 2. JAMA 2002, 288:1909-19|4.

47. Bodenheimer $\mathrm{T}, \mathrm{Wagner} \mathrm{EH}$, Grumbach $\mathrm{K}$ : Improving primary care for patients with chronic illness. JAMA 2002, 288: $1775-1779$

48. Wagner EH, Austin BT, Von Korff M: Improving outcomes in chronic illness. Manag Care $Q$ 1996, 4:12-25.

49. Wagner EH, Austin BT, Von Korff M: Organizing care for patients with chronic illness. Milbank $Q$ 1996, 74:5 I I-544.

50. Bodenheimer T, Lorig K, Holman H, Grumbach K: Patient selfmanagement of chronic disease in primary care. JAMA 2002, 288:2469-2475.

5I. Wagner EH, Grothaus LC, Sandhu N, Galvin MS, McGregor M, Artz $\mathrm{K}$, et al:: Chronic care clinics for diabetes in primary care: a system-wide randomized trial. Diabetes Care 200I, 24:695-700.

52. Wagner EH: Meeting the needs of chronically ill people. BMJ 200I, 323:945-946.

53. Starfield B: William Pickles Lecture. Primary and specialty care interfaces: the imperative of disease continuity. $\mathrm{Br} / \mathrm{Gen}$ Pract 2003, 53:723-729.

54. Shojania KG, Ranji SR, McDonald KM, Grimshaw JM, Sundaram V, Rushakoff RJ, et al:: Effects of quality improvement strategies for type $\mathbf{2}$ diabetes on glycemic control: a meta-regression analysis. JAMA 2006, 296:427-440.

55. Grimshaw JM, Shirran L, Thomas R, Mowatt G, Fraser C, Bero L, et al.: Changing provider behavior: an overview of systematic reviews of interventions. Med Care 200I, 39:II2-45.
56. Grol R, Wensing M: What drives change? Barriers to and incentives for achieving evidence-based practice. Med J Aust 2004, I 80:S57-S60

57. Bayless $M$, Martin $C:$ The team approach to intensive diabetes management. Diabetes Spectrum 1998, I I:33-37.

58. Prochaska JO, Velicer WF: The transtheoretical model of health behavior change. Am J Health Promot I 997, I 2:38-48.

59. Soumerai SB, Avorn J: Principles of educational outreach ('academic detailing') to improve clinical decision making. JAMA 1990, 263:549-556.

60. Funnell MM: Integrated approaches to the management of NIDDM patients. Diabetes Spectrum 1996, 9:55-59.

6I. NHG standard of care. NHG standard of care 2008

62. Rawal J, Barnett P, Lloyd BW: Use of structured letters to improve communication between hospital doctors and general practitioners. BMJ 1993, 307:1044

63. van Walraven C, Duke SM, Weinberg AL, Wells PS: Standardized or narrative discharge summaries. Which do family physicians prefer? Can Fam Physician 1998, 44:62-69.

64. Veldhuizen-Scott MK, Widmer LB, Stacey SA, Popovich NG: Developing and implementing a pharmaceutical care model in an ambulatory care setting for patients with diabetes. Diabetes Educ 1995, 21:117-123.

65. Jaber LA, Halapy H, Fernet M, Tummalapalli S, Diwakaran H: Evaluation of a pharmaceutical care model on diabetes management. Ann Pharmacother 1996, 30:238-243.

66. Berringer R, Shibley MC, Cary CC, Pugh CB, Powers PA, Rafi JA: Outcomes of a community pharmacy-based diabetes monitoring program. J Am Pharm Assoc (Wash) 1999, 39:791-797.

67. Campbell MK, Thomson S, Ramsay CR, Maclennan GS, et al.: Sample size calculator for cluster randomized trials. Comput Biol Med 2004, 34(2): I I3- I 25

68. Rowlands G, Sims J, Kerry S: A lesson learnt: the importance of modelling in randomized controlled trials for complex interventions in primary care. Fam Pract 2005, 22: I 32- I39.

69. Oakley A, Strange V, Bonell C, Allen E, Stephenson J: Process evaluation in randomised controlled trials of complex interventions. BMJ 2006, 332:413-4I6.

70. Flottorp S, Havelsrud K, Oxman AD: Process evaluation of a cluster randomized trial of tailored interventions to implement guidelines in primary care - why is it so hard to change practice? Fam Pract 2003, 20:333-339.

7I. Miller WL, McDaniel RR Jr, Crabtree BF, Stange KC: Practice jazz: understanding variation in family practices using complexity science. I Fam Pract 200I, 50:872-878.

72. Redfern J, McKevitt C, Wolfe CD: Development of complex interventions in stroke care: a systematic review. Stroke 2006 , 37:2410-2419.

73. Greenhalgh T, Robert G, Bate P, Kyriakidou O, Macfarlane F, Peacock R: How to spread good ideas. A systematic review of the literature on diffusion, dissemination and sustainability of innovations in health service delivery and organization. London 2004.

74. Carroll C, Patterson M, Wood S, Booth A, Rick J, Balain S: A conceptual framework for implementation fidelity. Implement SCi 2007, 2:40.

75. Grol R: Knowledge transfer in mental health care: how do we bring evidence into day-to-day practice? Can J Psychiatry 2008, 53:275-276.

76. The effect of intensive treatment of diabetes on the development and progression of long-term complications in insulindependent diabetes mellitus. The Diabetes Control and Complications Trial Research Group. N Engl J Med 1993, 329:977-986.

77. Renders CM, Valk GD, Griffin SJ, Wagner EH, Eijk VJ, Assendelft WJ: Interventions to improve the management of diabetes in primary care, outpatient, and community settings: a systematic review. Diabetes Care 200I, 24:1821-1833.

78. Krein SL, Klamerus ML, Vijan S, Lee JL, Fitzgerald JT, Pawlow A, et al.: Case management for patients with poorly controlled diabetes: a randomized trial. Am I Med 2004, I I 6:732-739.

79. Olivarius NF, Beck-Nielsen H, Andreasen AH, Horder M, Pedersen PA: Randomised controlled trial of structured personal care of type 2 diabetes mellitus. BMJ 200I, 323:970-975.

80. Parchman ML, Pugh JA, Culler SD, Noel PH, Arar NH, Romero RL, et al.: A group randomized trial of a complexity-based organizational intervention to improve risk factors for diabetes com- 
plications in primary care settings: study protocol. Implement Sci 2008, 3:15.

8I. Bradley F, Wiles R, Kinmonth AL, Mant D, Gantley M: Development and evaluation of complex interventions in health services research: case study of the Southampton heart integrated care project (SHIP). The SHIP Collaborative Group. BMJ 1999, 3 18:71 I-7I5.

Publish with Bio Med Central and every scientist can read your work free of charge

"BioMed Central will be the most significant development for disseminating the results of biomedical research in our lifetime. " Sir Paul Nurse, Cancer Research UK

Your research papers will be:

- available free of charge to the entire biomedical community

- peer reviewed and published immediately upon acceptance

- cited in PubMed and archived on PubMed Central

- yours - you keep the copyright

Submit your manuscript here:

http://www.biomedcentral.com/info/publishing_adv.asp
BioMedcentral 